Research Article

\title{
Sales Strategy considering Advertising in Advance-Selling and Spot-Selling Integration Mode for Fresh Product
}

\author{
Bo Zhang $\mathbb{D}^{1},{ }^{1}$ Lan Yang $\mathbb{D}^{2},{ }^{2}$ Meng Zhang $\mathbb{D}^{2},{ }^{2}$ and Yanhui Li $\mathbb{D}^{2}$ \\ ${ }^{1}$ School of Economics, Wuhan Business University, Wuhan 430056, China \\ ${ }^{2}$ School of Information Management, Central China Normal University, Wuhan 430079, China \\ Correspondence should be addressed to Yanhui Li; yhlee@mail.ccnu.edu.cn
}

Received 22 April 2021; Revised 12 June 2021; Accepted 13 July 2021; Published 21 July 2021

Academic Editor: Tingsong Wang

Copyright (c) 2021 Bo Zhang et al. This is an open access article distributed under the Creative Commons Attribution License, which permits unrestricted use, distribution, and reproduction in any medium, provided the original work is properly cited.

In this paper, we look into the optimal sales strategy of e-commerce platform which sells fresh-product advertising in advanceselling period and spot-selling period, respectively, when advance-selling and spot-selling integration mode is applied. The study found that, with the increase of advertising investment, the marginal benefit of e-commerce platform is declining; whether advertising during the advance-selling period or the advertising during the spot-selling period, the e-commerce platform can improve its profit, but under the same advertising effect factor, the optimal advertising investment for the sale period is smaller, and the profit when advertising in the advance-selling period is greater. When advertising in different periods, the optimal advertising and price strategy depends on the maximum valuation of consumers about the product and the advertising effect factor.

\section{Introduction}

In recent years, e-commerce developed rapidly. Especially, during the COVID-19, e-commerce retailers all over the world have increased their sales volume due to its unique advantages. E-commerce of fresh agricultural products accounts for a large proportion. Taking the Chinese market as an example, in 2020, the transaction volume of China's fresh e-commerce was $\$ 56.04$ billion, and it is expected to reach $\$ 123.1148$ billion in 2023 [1]. As a flexible sales mode, advance selling is widely used in various e-commerce retailers. For example, on September 21, 2017, "T-mall advance-selling" sold 140,000 "fresh" hairy crabs in one minute, setting a record in China's fresh industry. Advance selling is affected not only by commodity price factors but also by other nonprice factors (advertising, quality, etc.) $[2,3]$. With the development of media channels and information technology, advertising has an increasing impact on consumers' purchase decisions [4]. In reality, e-commerce retailers mostly adopt the mode of combining advance selling and spot selling, and some research studies have shown that the integration of the two modes not only can expand demand and reduce risk but also can effectively solve the problem of high inventory cost $[2,5]$.

Many scholars focus on the pricing strategy, consumer behavior, and advance-selling time strategy of products in the advance-selling period. For example, Prasad et al. [6] have studied the advance-selling price and inventory decisions in the advance-selling period and the spot-selling period and believe that retailers should apply different sales strategies according to the consumer parameters and market parameters. Xiao et al. [7] studied the seller's equilibrium pricing strategy under two classical earlyselling pricing schemes (dynamic pricing scheme and price commitment scheme). Cheng et al. [8] considered the presale strategy of the newsvendor model under the influence of dual marketing. The above papers have analyzed the optimal sales strategy of pricing. While the suppliers increase profits, the consumers become more and more intelligent. Therefore, considering the behavior of the consumer has become a new research direction in the field of advance selling. Yu et al. [9] studied the optimal decisions of presale and cash sale of new products and innovative products considering consumer differences and 
strategic consumer response. Lim and Tang [10] considered the market composed of short-sighted consumers, forward-looking consumers, and investors, explored the presale strategy of monopoly sellers, and then proposed a dynamic behavior model of investors. Zhao and Stecke [11] studied the choice of three preorder strategies (no presale, moderate presale and deep presale) of retailers considering consumption loss aversion. In the case of presale, time is an important factor. How retailers choose the presale time to accurately grasp the market demand is a new problem. Chew et al. [12] discussed the problem of the multistage perishable product-ordering strategy. Schaaf and Skiera [13] studied the effect of time preferences on optimal prices and profitability of advance selling. Reviewing the papers on presale strategy, we can see that the research content of presale strategy has been relatively rich, the presale mode has been successfully applied to the online sales of many commodities, and the application of fresh agricultural products is in the exploratory stage. Maihami and Kamalabadi [14] studied the joint pricing and inventory control of noninstantaneous deteriorating items by establishing a time-dependent function model. From the perspective of competition, He et al. [15] analyzed the online presale mode of fresh products. Fan et al. [16] focused on the business strategy of fresh products' retailers and studied the dynamic pricing strategy and supplement policy of multibatch fresh agricultural products with realtime freshness through the revenue management dynamic programming model of consumer choice behavior. Zhang et al. [17] studied three presale strategies and service efforts of the fresh seasonal agricultural products' supply chain. Research on the presale strategy of fresh agricultural products is ascending. It is mainly focusing on presale pricing and fresh agricultural product ordering. Few scholars consider advertising investment as a decision variable in this field though it is an important factor influencing consumers' purchase decisions.

To sum up, few studies took both advance-selling advertising and pricing into account and set the fresh agricultural products' market as the research background. In addition, few scholars consider the impact of consumer behavior and consumer heterogeneity on sales strategy.

Therefore, based on the integrated environment of advance selling and spot selling, this paper discusses the pricing and advertising investment strategies of fresh agricultural products' e-commerce retailers considering consumers' knowledge and demand randomness. Considering the limited investment amount of most enterprises in the real environment, this paper studies the optimal sales strategies of e-commerce retailers for advertising investment in the advance-selling period or the spot-selling period, so as to provide decision-making reference for enterprises to formulate reasonable sales methods.

\section{Problem Formulation and Symbol Explanation}

This paper assumes that the e-commerce retailers of fresh agricultural products sell in two stages: the first stage is the advance-selling period, in which consumers can order fresh agricultural products in advance; the second stage is the spot-selling period, in which consumers can purchase directly, and the consumers participating in the advance selling and spot selling are getting the real products. Before the product is officially on the market, that is, in the advanceselling period, e-commerce retailers can advertise the product to expand the sales in the advance-selling period; after the product is on the market, that is, in the spot-selling period, consumers will actively search for the sales information of fresh agricultural products, and sellers can also choose to rely on their larger demand base to expand the sales in the spot-selling period. Therefore, this paper studies the optimal pricing, optimal advertising investment, and optimal order quantity of e-commerce retailers in different periods.

The research in this paper is consistent with the following assumptions:

(1) The advertising investment of e-commerce retailers is $x, x \in(0,1)$, the advertising effect factor is $b$, and the influence of advertising on demand is $b \sqrt{x}[18]$.

(2) The consumers' number of the product without advertising is 1 . According to whether the consumers know the advance-selling information of the e-commerce retailer, the consumers are divided into two categories. One is the informed consumers, whose proportion is $\gamma$, and the other is the uninformed consumers, whose proportion is $1-\gamma[4,19]$. After the advance-selling period, the proportion of informed consumers is $\gamma+b \sqrt{x}$.

(3) In the spot-selling period, the unit price of the products is $p$ and the unit cost is $c_{2}$. In the advanceselling period, the unit price of the products is $\alpha p$, $0 \leq \alpha \leq 1$, and the unit cost is $c_{1}$. At the end of the advance-selling period, the e-commerce retailer decides the order quantity $Q$ of the whole sales period. Considering that fresh agricultural products are easy to rot, e-commerce retailers need to invest in fresh-keeping costs in the spot-selling period to ensure the consistent quality of the products sold. Therefore, $c_{1}<c_{2}$.

(4) After the end of the sales period, the quality of the product decreases rapidly, the demand disappears, and the residual value of the product is 0 .

(5) Suppose that the consumer's valuation of the product, $v$, obeys the uniform distribution $U\left(0, v_{0}\right)$, the density function is $u(v)$, and the distribution function is $U(v)$. When informed consumers enter the market in the advance-selling period, $v \geq \alpha p$, they buy products in the advance selling; $v \geq p$, at that time, and they buy products in the spot-selling period. $\varepsilon$ is a demand random variable which belongs to $[A, B]$; its density function is $f(\varepsilon)$, and the distribution function is $F(\varepsilon)$. Without losing generality, it is assumed that $c_{1}<p<v_{0}$. 


\section{Optimal Strategy Analysis}

3.1. The Optimal Decision of Advertising Investment in Advance-Selling Period $(A)$. We assume $x_{A}$ is the advertising investment of e-commerce retailers in the advance-selling period and $\alpha_{A} p_{A}$ is the product price. The consumer demand function in the advance-selling period is as follows:

$$
D_{A 1}=\left(\gamma+b \sqrt{x_{A}}\right) \int_{\alpha_{A} p_{A}}^{v_{0}} u(v) \mathrm{d} v .
$$

The profit function of e-commerce retailers at this stage is as follows:

$$
\pi_{A 1}=\left(\alpha_{A} p_{A}-c_{1}\right)\left(\gamma+b \sqrt{x_{A}}\right) \int_{\alpha_{A} p_{A}}^{v_{0}} u(v) \mathrm{d} v-x_{A}
$$

In the spot-selling period, e-commerce retailers do not invest in advertising, and the price of products is $p_{A}$. The consumer demand function is

$$
D_{A 2}=(1-\gamma) \int_{p_{A}}^{v_{0}} u(v) \mathrm{d} v+\varepsilon
$$

The total demand under the integrated mode of advertising in the advance-selling period is $D_{A}=D_{A 1}+D_{A 2}+$ $\mathcal{E}$, so the total profit is

$$
\pi \pi_{A}= \begin{cases}\left(\alpha_{A} p_{A}-c_{1}\right) D_{A 1}-x_{A}+p_{A} D_{A 2}-c_{2}\left(Q-D_{A 1}\right), & D_{A} \leq Q \\ \left(\alpha_{A} p_{A}-c_{1}\right) D_{A 1}-x_{A}+\left(p_{A}-c_{2}\right)\left(Q-D_{A 1}\right), & D_{A}>Q\end{cases}
$$

Let $z=Q-\left(D_{1}-D_{2}\right)$; then,

$$
\pi_{A}= \begin{cases}\left(\alpha_{A} p_{A}-c_{1}\right) D_{A 1}-x_{A}+p_{A}\left(D_{A 2}+\varepsilon\right)-c_{2}\left(D_{A 2}+z\right), & \varepsilon \leq z, \\ \left(\alpha_{A} p_{A}-c_{1}\right) D_{A 1}-x_{A}+\left(p_{A}-c_{2}\right)\left(D_{A 2}+z\right), & \varepsilon>z .\end{cases}
$$

After simplification, it is as follows:

$$
\pi_{A}=\left(\alpha_{A} p_{A}-c_{1}\right)\left(\gamma+b \sqrt{x_{A}}\right) \int_{\alpha_{A} p_{A}}^{v_{0}} u(v) \mathrm{d} v-x_{A}+\left(p_{A}-c_{2}\right)\left((1-\gamma) \int_{p_{A}}^{v_{0}} u(v) \mathrm{d} v+z\right)-p_{A} \int_{A}^{Z} F(u) \mathrm{d} u .
$$

From the negative definite of the Hessian Matrix, we can see that the function $\pi_{A}$ is a joint concave function of $\alpha_{A}$ and $x_{A}$, and the optimal solution can be obtained by the firstorder condition.

Proposition 1. When $b \sqrt{x_{A}}<2 v_{0}\left(\alpha_{A} p_{A}-c_{1}\right)\left(v_{0}-\alpha_{A}\right.$ $\left.p_{A}\right) / b\left(v_{0}-2 \alpha_{A} p_{A}-c_{1}\right)^{2}$, the optimal discount, advertising investment, and profit in the advance-selling period are as follows:

$$
\begin{aligned}
\alpha_{A}^{*} & =\frac{v_{0}+c_{1}}{2 p_{A}}, \\
\pi_{A_{1}}^{*} & =\frac{\gamma\left(v_{0}-c_{1}\right)^{2}}{4 v_{0}}+\frac{b^{2}\left(v_{0}-c_{1}\right)^{4}}{64 v_{0}{ }^{2}}, \\
x_{A}^{*} & =\frac{\left(v_{0}-\alpha_{A} p_{A}\right)^{2}\left(\alpha_{A} p_{A}-c_{1}\right)^{2} b^{2}}{4 v_{0}{ }^{2}} .
\end{aligned}
$$

Proof.

$\left(\partial \pi_{A 1} / \partial \alpha_{A}\right)=\left(\gamma+b \sqrt{x_{A}}\right)\left(p_{A}\left(v_{0}-2 \alpha_{A} p_{A}-c_{1}\right) / v_{0}\right)$,

$$
\begin{aligned}
\frac{\partial^{2} \pi_{A 1}}{\partial \alpha_{A}^{2}} & =-2 p_{A}^{2}<0, \\
\frac{\partial \pi_{A 1}}{\partial x_{A}} & =\frac{b\left(\alpha_{A} p_{A}-c\right)_{1}\left(v_{0}-\alpha_{A} p_{A}\right)}{2 v_{0} \sqrt{x_{A}}}-1,
\end{aligned}
$$$$
\frac{\partial^{2} \pi_{A 1}}{\partial x_{A}^{2}}=-\frac{b\left(\alpha_{A} p_{A}-c_{1}\right)\left(v_{0}-\alpha_{A} p_{A}\right)}{4 v_{0}} x_{A}^{-3 / 2}<0,
$$

$$
\frac{\partial^{2} \pi_{A 1}}{\partial \alpha_{A} \partial x_{A}}=\frac{b p_{A}\left(v_{0}-2 \alpha_{A} p_{A}-c_{1}\right)}{2 v_{0}} .
$$

When $b \sqrt{x_{A}}<\left(2 v_{0}\left(\alpha_{A} p_{A}-c_{1}\right)\left(v_{0}-\alpha_{A} p_{A}\right) / b\left(v_{0}-2 \alpha_{A}\right.\right.$ $\left.\left.p_{A}-c_{1}\right)^{2}\right)$,

$$
\frac{\partial^{2} \pi_{A 1}}{\partial \alpha_{A}{ }^{2}} \frac{\partial^{2} \pi_{A 1}}{\partial x_{A}^{2}}-\left(\frac{\partial^{2} \pi_{A 1}}{\partial \alpha_{A} \partial x_{A}}\right)^{2}>0
$$

It shows that $\pi_{A 1}$ is a joint concave function of $\alpha_{A}$ and $x_{A}$, so the optimal solution of $\alpha_{A}$ and $x_{A}$ can be obtained by $\partial \pi_{A 1} / \partial \alpha_{A}=0$ and $\partial \pi_{A 1} / \partial x_{A}=0$ : 


$$
\begin{aligned}
\alpha_{A}^{*} & =\frac{v_{0}+c_{1}}{2 p_{A}}, \\
x_{A}^{*} & =\frac{\left(v_{0}-\alpha_{A} p_{A}\right)^{2}\left(\alpha_{A} p_{A}-c_{1}\right)^{2} b^{2}}{4 v_{0}^{2}}, \\
\pi_{A 1}^{*} & =\frac{\gamma\left(v_{0}-c_{1}\right)^{2}}{4 v_{0}}+\frac{b^{2}\left(v_{0}-c_{1}\right)^{4}}{64 v_{0}^{2}} .
\end{aligned}
$$

Proposition 1 shows that in the advance-selling period, the impact of advertising investment on profit is limited, and there is the best advertising investment. Among them, advertising investment $x_{A}$ is positively correlated with the advertising effect factor $b$, indicating that e-commerce retailers tend to increase advertising investment when the advertising effect of products on consumers increases. The optimal discount in the advance-selling stage is inversely proportional to the price in the second stage (spot-selling period), which indicates that when the spot-selling price is higher, the discount coefficient set by the e-commerce retailer in the advance-selling period should be smaller, which can attract more customers; while when the spot-selling price is lower, the e-commerce retailer does not need to provide a large discount in the advance-selling period, which can also obtain the best profit.

Proposition 2. The optimal price in the spot-selling period is as follows:

$$
p_{A}(z)^{*}=\frac{(1-\gamma)\left(v_{0}+c_{2}\right)+\alpha_{A}\left(\gamma+b \sqrt{x_{A}}\right)\left(v_{0}+c_{1}\right)+v_{0} z-\left(\int_{A}^{Z} F(u) \mathrm{d} u\right)}{2\left((1-\gamma)+\alpha_{A}^{2}\left(\gamma+b \sqrt{x_{A}}\right)\right)} .
$$

The optimal price increases with the increase of $z$, that is, with the increase of random variables. The optimal order quantity in the spot period is

$$
Q(z)_{A}^{*}=\frac{v_{0}-c_{1}}{2 v_{0}}\left(\gamma+\frac{b^{2}\left(v_{0}-c_{1}\right)^{2}}{8 v_{0}}\right)+(1+\gamma) \frac{v_{0}-p_{A}(z)^{*}}{v_{0}} .
$$

Proof. From the first derivative $\partial \pi_{A} / \partial p_{A}=0$, the optimal price of the spot-selling period can be obtained, and there is $\partial p_{A}(z)^{*} / \partial z=v_{0} \bar{F}(z) / 2(1-\gamma)>0$, which shows that $p_{A}(z)^{*}$ is a monotone increasing function of $z$, that is, the optimal price increases with the increase of $z$.

The optimal solution of $Q$ can be obtained by taking the optimal solution of the first stage into $Q=D_{1}+D_{2}+z$ and $\left(\partial Q(z)_{A}^{*} / \partial z\right)=1-\bar{F}(z)>0$. It shows that $Q(z)_{A}^{*}$ is a monotone increasing function of $z$, that is, the optimal order quantity increases with the increase of $z$.

Proposition 2 shows that the optimal price is positively correlated with the demand random variable $\varepsilon$ because when $\varepsilon$ increases, the demand increases. To ensure that the demand is met to the maximum extent, the optimal order quantity will increase accordingly. In order to compensate for the inventory cost and preservation cost caused by the increase of inventory, e-commerce retailers will increase the sales price.

Proposition 3. When the point satisfies formula (12), it is the only extreme point that maximizes the total profit function:

$$
\frac{\partial \pi_{A}(z)}{\partial z}=\frac{v_{0} \bar{F}(z)\left(z+(1-\gamma)\left(1-p_{A}(z)^{*}\right)\right)}{2\left(1-\gamma+\alpha_{A}^{2}\left(\gamma+b \sqrt{x_{A}}\right)\right)}+\left(p_{A}(z)^{*}-c_{2}\right)\left(1-\frac{v_{0} \bar{F}(z)}{2}\right)-p_{A}(z)^{*} F(z)=0 .
$$

That is, there is a unique maximum of the total profit when the e-commerce retailer invests in advertising in the advance-selling period.
Proof. Put the optimal solution of $p(z)$ brought into the total profit function; if the solution with the first derivative of 0 exists and is unique, this point is the point with the largest total profit function:

$$
\frac{\partial \pi_{A}(z)}{\partial z}=\frac{v_{0} \bar{F}(z)\left(z+(1-\gamma)\left(1-p_{A}(z)^{*}\right)\right)}{2\left(1-\gamma+\alpha_{A}^{2}\left(\gamma+b \sqrt{x_{A}}\right)\right)}+\left(p_{A}(z)^{*}-c_{2}\right)\left(1-\frac{v_{0} \bar{F}(z)}{2}\right)-p_{A}(z)^{*} F(z)=0 .
$$

Let the above formula be $S(z)$. Let $v_{0}=1$ to make the calculation convenient, and it can be proved that 


$$
\frac{\partial^{2} S(z)}{\partial z^{2}}=-3 f(z)-f(z) \bar{F}(z)+2 f(z) F(z)-\frac{\partial f(z)}{\partial z}\left(f(z)+(1-\gamma)\left(1+c_{2}\right)+z-\int_{A}^{Z} F(u) \mathrm{d} u<0\right)
$$

It is shown that $S(z)$ is a convex function about $z$, that is, $S(z)=0$ has two solutions. If $F(A)=0$ and $F(B)=1$ are known, $S(A)>0$ and $S(B)>0$ can be obtained, so $S(z)=0$ has a unique solution. Since $\partial \pi_{A}(z) / \partial z=S(z), \pi_{A}(z)$ is a function of $z$ increasing first and then decreasing, and when $\partial \pi_{A}(z) / \partial z=0$, the maximum value is obtained.

Proposition 3 shows that the model has an optimal solution and the optimal solution is unique. It shows that e-commerce retailers can have the optimal sales strategy and get the maximum revenue when they invest in advertising in the advance-selling period. The detailed analysis results will be described in Section 4.

3.2. Optimal Decision of Advertising Investment in Spot-Selling Period $(R)$. We assume $x_{R}$ is the advertising costs in spot- selling period, $\alpha_{R} p_{R}$ is the selling price of the products in advance-selling period, and $p_{R}$ is the selling price of the products in the spot-selling period. The demand in the advance-selling period $D_{R 1}$ and the spot-selling period $D_{R 2}$ are, respectively, as follows:

$$
\begin{aligned}
& D_{R 1}=\frac{\gamma\left(v_{0}-\alpha_{R} p_{R}\right)}{v_{0}}, \\
& D_{R 2}=\left(1-\gamma+b \sqrt{x_{R}}\right) \frac{v_{0}-p_{R}}{v_{0}}+\varepsilon .
\end{aligned}
$$

Thus, the profit of the advance-selling period and spotselling period are as follows:

$$
\begin{aligned}
& \pi_{R 1}=\gamma\left(\alpha_{R} p_{R}-c_{1}\right) \frac{\left(v_{0}-\alpha_{R} p_{R}\right)}{v_{0}} \\
& \pi_{R 2}=\left(p_{R}-c_{2}\right)\left(z+\left(1-\gamma+b \sqrt{x_{R}}\right) \frac{v_{0}-p_{R}}{v_{0}}\right)-p_{R} \int_{A}^{Z} F(u) \mathrm{d} u-x_{R} .
\end{aligned}
$$

Let $z=Q-D_{R 1}-D_{R 2}$.
Then, the total profit of the e-commerce retailer under the integrated mode of advertising in the spot-selling period is as follows:

$$
\pi_{R}=\gamma\left(\alpha_{R} p_{R}-c_{1}\right) \frac{\left(v_{0}-\alpha_{R} p_{R}\right)}{v_{0}}+\left(p_{R}-c_{2}\right)\left(\left(z+\left(1-\gamma+b \sqrt{x_{R}}\right) \frac{v_{0}-p_{R}}{v_{0}}\right)-p_{R} \int_{A}^{Z} F(u) \mathrm{d} u-x_{R} .\right.
$$

Proposition 4. When advertising strategy is put into the spot-selling period, the optimal discount is

$$
\alpha_{R}^{*}=\frac{v_{0}+c_{1}}{2 p_{R}}
$$

When $\sqrt{x_{R}}<2\left(p_{R}-c_{2}\right)\left(v_{0}-p_{R}\right)\left(1-\gamma+\alpha_{R}^{2} \gamma\right) / b\left(v_{0}-\right.$ $\left.2 p_{R}+c_{2}\right)^{2}-2\left(p_{R}-c_{2}\right)\left(v_{0}-p_{R}\right)$, the optimal advertising investment, price, and order quantity are as follows:

$$
\begin{aligned}
& x_{R}^{*}=\left(\frac{b\left(p_{R}-c_{2}\right)\left(v_{0}-p_{R}\right)}{2 v_{0}}\right)^{2}, \\
& p_{R}^{*}=\frac{\left(1-\gamma+b \sqrt{x_{R}}\right)\left(v_{0}+c_{2}\right)+v_{0}\left(z-\int_{A}^{Z} F(u) \mathrm{d} u\right)}{2\left(1-\gamma+b \sqrt{x_{R}}\right)}, \\
& Q_{R}^{*}=\frac{\gamma\left(v_{0}-c_{1}\right)}{2 v_{0}}+\left(1-\gamma+\frac{b^{2}\left(p_{R}^{*}-c_{2}\right)\left(v_{0}-p_{R}^{*}\right)}{2 v_{0}}\right) \frac{v_{0}-p_{R}{ }^{*}}{v_{0}}+z .
\end{aligned}
$$


Proof. The optimal discount $\alpha_{R}{ }^{*}$ is obtained by finding the first derivative of $\pi_{R}$ on $\alpha_{R}$ :

$$
\begin{aligned}
\frac{\partial \pi_{R}}{\partial p_{R}} & =\frac{\alpha_{R} \gamma\left(v_{0}+c_{1}\right)+\left(1-\gamma+b \sqrt{x_{R}}\right)\left(v_{0}+c_{2}\right)}{v_{0}}-p \frac{2 \alpha_{R}^{2} \gamma+2\left(1-\gamma+b \sqrt{x_{R}}\right)}{v_{0}}+z-\int_{A}^{Z} F(u) \mathrm{d} u \\
\frac{\partial^{2} \pi_{R}}{\partial p_{R}^{2}} & =-\frac{2 \alpha_{R}^{2} \gamma+2\left(1-\gamma+b \sqrt{x_{R}}\right)}{v_{0}}<0 \\
\frac{\partial \pi_{R}}{\partial x_{R}} & =\frac{b\left(p_{R}-c_{2}\right)\left(v_{0}-p_{R}\right)}{2 v_{0} \sqrt{x_{R}}} \\
\frac{\partial^{2} \pi_{R}}{\partial x_{R}^{2}} & =-\frac{b\left(p_{R}-c_{2}\right)\left(v_{0}-p_{R}\right)}{2 v_{0} x_{R}^{3 / 2}}<0 \\
\frac{\partial^{2} \pi_{R}}{\partial x_{R} \partial p_{R}} & =\frac{b\left(v_{0}+c_{2}-2 p_{R}\right)}{2 v_{0} \sqrt{x_{R}}}
\end{aligned}
$$

When $\sqrt{x_{R}}<2\left(p_{R}-c_{2}\right)\left(v_{0}-p_{R}\right)\left(1-\gamma+\alpha_{R}^{2} \gamma\right) / b\left(\left(v_{0}+\right.\right.$ $\left.\left.c_{2}-2 p_{R}\right)^{2}-2\left(p_{R}-c_{2}\right)\left(v_{0}-p_{R}\right)\right)$,

$$
\frac{\partial^{2} \pi_{R}}{\partial p_{R}^{2}} \frac{\partial^{2} \pi_{R}}{\partial x_{R}^{2}}-\left(\frac{\partial^{2} \pi_{R}}{\partial x_{R} \partial p_{R}}\right)^{2}>0,
$$

and it shows that $\pi_{R}$ is a joint concave function of $x_{R}$ and $p_{R}$, so the optimal solution of $x_{R}$ and $p_{R}$ can be obtained by $\partial \pi_{R} / \partial p_{R}=0$ and $\partial \pi_{R} / \partial x_{R}=0$, and the optimal solution has been given.

Proposition 4 shows that in the spot-selling period, the impact of advertising investment on the total profit is limited, and there is the best advertising investment, in which the advertising investment $x_{R}$ is positively correlated with the advertising effect factor $b$, indicating that when the advertising effect of products on consumers increases, e-commerce retailers tend to increase advertising investment.

Proposition 5. We can prove Proposition 5 uses the same method as Proposition 3. When the point satisfies formula (23), it is the only extreme point that maximizes the total profit function:

$$
\begin{gathered}
\frac{\partial \pi_{R}}{\partial z}=\left(p_{R}-c_{2}\right)\left(1-\frac{(1-\gamma) \bar{F}(z)}{2\left(1-\gamma+b \sqrt{x_{R}}\right)}+\frac{\left(b^{2}\left(v_{0}-p_{R}\right)-\left(1+b^{2}\right)\left(p_{R}-c_{2}\right)\right)\left(v_{0}-p_{R}\right) \bar{F}(z)}{4 v_{0}\left(1-\gamma+b \sqrt{x_{R}}\right)}\right), \\
-\frac{b^{2} \bar{F}(z)\left(\left(p_{R}-c_{2}\right)\left(v_{0}-p_{R}\right)^{2}-\left(p_{R}-c_{2}\right)^{2}\left(v_{0}-p_{R}\right)\right)}{2 v_{0}\left(1-\gamma+b \sqrt{x_{R}}\right)}-\frac{z^{2} v_{0} \bar{F}(z)}{4\left(1-\gamma+b \sqrt{x_{R}}\right)}-p_{R}, \quad z=0 .
\end{gathered}
$$

That is, there is a unique maximum of the total profit of e-commerce retailers when they invest in advertising in the spot-selling period.

Proposition 5 shows that there is also a unique optimal solution for advertising strategy in the spot-selling period. No matter if advertising investment is put in the advance-selling or spot-selling period, the optimal solution exists, but it is inconsistent. The optimal solution is affected by numerous parameters. Once these parameters are determined, the optimal solution can be obtained. The advertising strategy can provide an important reference value for solving practical problems.

The specific analytical formula of the optimal solution in these two cases cannot be given, but it can be analyzed by numerical simulation, so the strategy comparative analysis is described in the part of example analysis.

\section{Strategy Analysis}

The results of this paper are verified and further analyzed by numerical examples. Using MATLAB 2014 for numerical analysis, referring to the previous research studies $[20,21]$ on parameter settings, we assume that the maximum estimated value of consumer product $v_{0}=1$, the unit cost of fresh agricultural products $c_{1}=0.2$ in the advance-selling period, the unit cost of fresh agricultural products $c_{2}=0.3$ in the spot-selling period, the advertising effect factor $b=0.8$, the initial ratio of informed consumers $\gamma=0.3$, and 
the random demand factor $\varepsilon$ obeys the uniform distribution of $[0,1]$.

4.1. Analysis of Advertising Strategy. This paper studies the advertising strategy considering consumer valuation and the comparative analysis of the two cases. Consider the case of advertising investment in the advance-selling period, keep other parameters unchanged, and the maximum consumer valuation values are $0.5,0.8$, and 1.0 , respectively, and the influence of advertising effect factor $b$ on the optimal advertising investment $x$ is shown in Figure 1.

Figure 1(a) shows that when consumers' valuation of products is large, the advertising investment increases with the increase of the advertising effect factor. With the increase of the maximum valuation, the proportion of consumers whose product valuation is greater than the sales price will increase; when the advertising effect factor is larger, it shows that advertising can effectively improve consumers' demand for fresh agricultural products. Therefore, with the increase of consumers' product valuation, e-commerce retailers should increase their advertising investment.

Figure 1(b) shows that, under the same advertising effect factor, the optimal advertising investment in the spot-selling period is greater than that in the advance-selling period. This shows that, in the spot-selling period, advertising needs to pay more cost. This is because there is an increase in demand due to price discounts in the advance-selling period, so there is no need to invest too much advertising cost.

4.2. Comparative Analysis of Profit. The time of advertising investment would influence the profit. Figure 2 shows the impact of advertising investment on profit in different periods (advance-selling period and spot-selling period).

Figure 2(a) shows that when there is no advertising investment in the advance-selling period, the profit in the spot-selling period is greater than that in the advance-selling period, but the total profit is lower. After the advertising investment, the profits in the spot-selling period and the advance-selling period increase. With the increase of advertising investment, the profit in the advance-selling period gradually approaches that in the spot-selling period, and the total profit increases greatly.

Figure 2(b) shows the following. (1) When advertising is put in the advance-selling period, the total profit will increase with the increase of advertising investment and tend to be stable, indicating that the increased range of total profit with advertising investment is limited, and the marginal benefit decreases, which is consistent with Proposition 1. (2) When advertising is put in the spot-selling period, the total profit will first increase and then decrease with advertising investment, indicating that excessive advertising investment in the spot-selling period will cause profit loss. (3) With the increase of advertising investment, the total profit of advertising in the advance-selling period is greater than that in the spot-selling period.

The profit function is influenced by many factors, among which the demand random factor is uncontrollable.
Therefore, we compare the total profit of advertising in the advance-selling period with that in the spot-selling period with the change of demand random factor, as shown in Figure 3.

Figure 3 shows

(1) When the demand stochastic factor $z>0$, the total profit of advertising in the advance-selling period and the total profit of advertising in the spot-selling period first increases and then decreases with the increase of the demand stochastic factor; a certain range of demand uncertainty can increase the e-commerce retailer's revenue, but once the uncertainty is too large, the e-commerce retailer will not be able to estimate the order quantity, resulting in some losses.

(2) From the trend of profit function, we can see that there are optimal profit points for the total profit of advertising in the advance-selling period and the total profit of advertising in the spot-selling period, which verifies Propositions 3 and 5 of this paper.

(3) When the demand stochastic factor $z>0$, e-commerce retailers should choose to invest in the advertising cost in the cash period; at this time, the profit is greater; when the demand stochastic factor $z<0$, e-commerce retailers should choose to invest in the advertising cost in the advance-selling period; at this time, they can get more profits.

4.3. Comparative Analysis of Price and Order Quantity. In order to study the influence of advertising investment on the optimal price and the optimal order quantity, this paper draws the influence of the optimal price and the optimal order quantity changing with the advertising investment, as shown in Figure 4.

Figure 4 shows

(1) In the case of advertising in the advance-selling period, the price and optimal order quantity increase with the increase of advertising investment. When the advertising investment increases, the cost of e-commerce retailers increases, so the price will increase, and the demand will increase, so the order quantity will increase.

(2) When the advertising investment is small, if you choose to put the advertising in the cash period, the optimal pricing of the product in the cash period is higher than that in the advance-selling period. When the advertising investment is large, if you choose to put the advertising in the cash period, the optimal pricing of the product in the cash period is lower than that in the advance-selling period.

(3) With the increase of advertising investment, whether in the advance-selling period or the spot-selling period, the order quantity of products has increased, that is, the demand for products has increased, but the consumer demand is greater in the advanceselling period. 


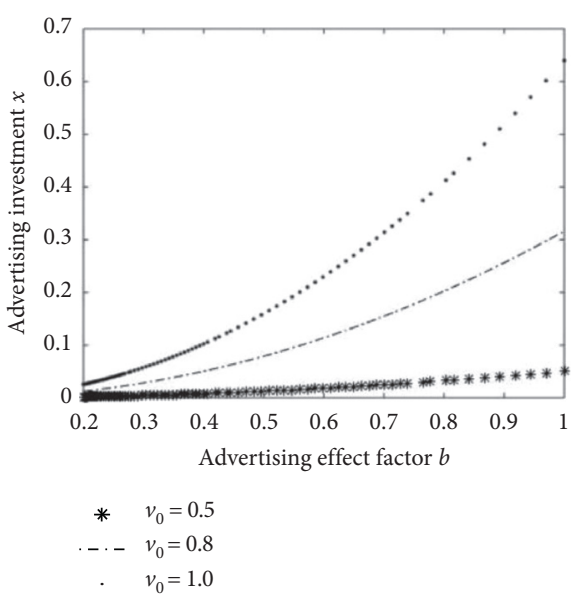

(a)

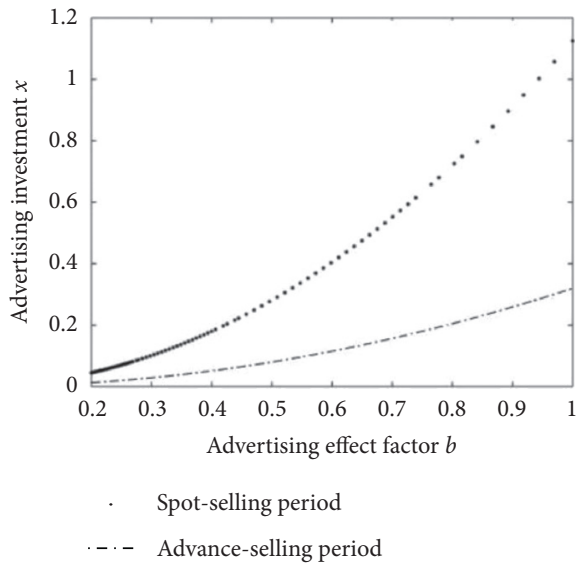

(b)

Figure 1: Analysis of advertising strategies under different advertising effect factors.

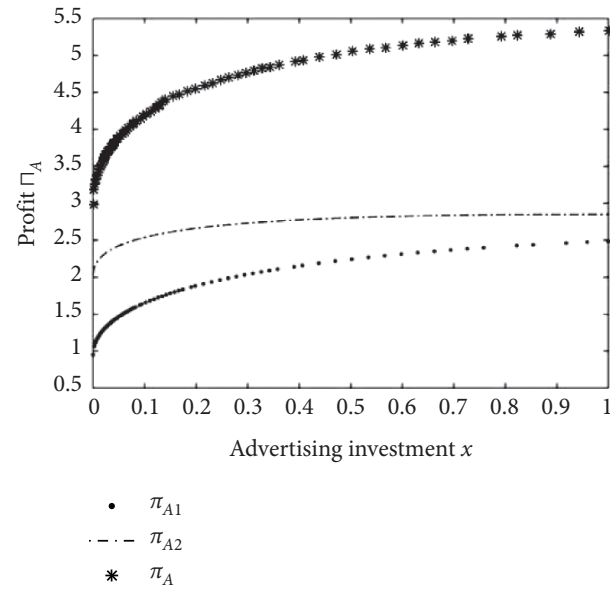

(a)

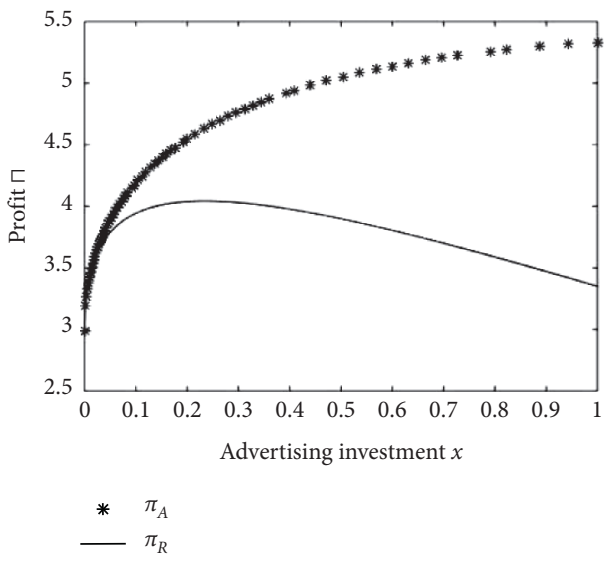

(b)

FIGURE 2: The impact of advertising investment on profit.

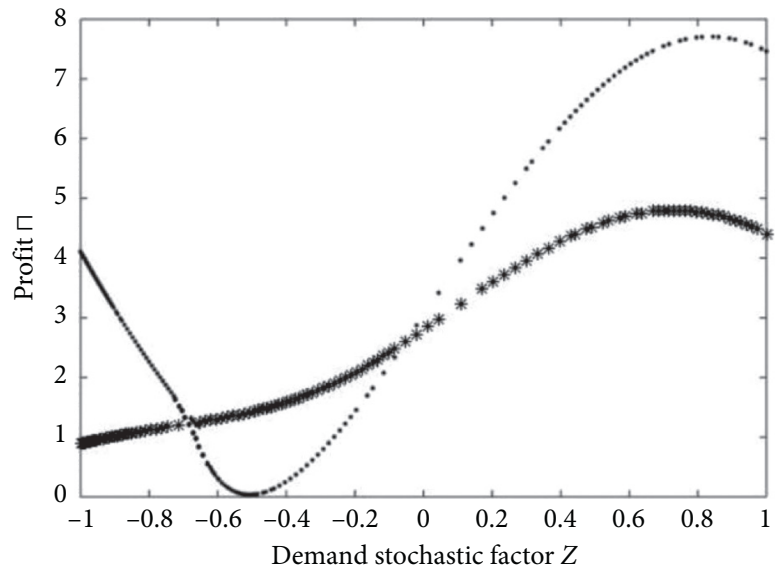

$$
\begin{aligned}
& * \pi_{A} \\
& \text { - } \pi_{R}
\end{aligned}
$$

FIgURE 3: The influence of demand stochastic factor on total profit under different periods of advertising. 


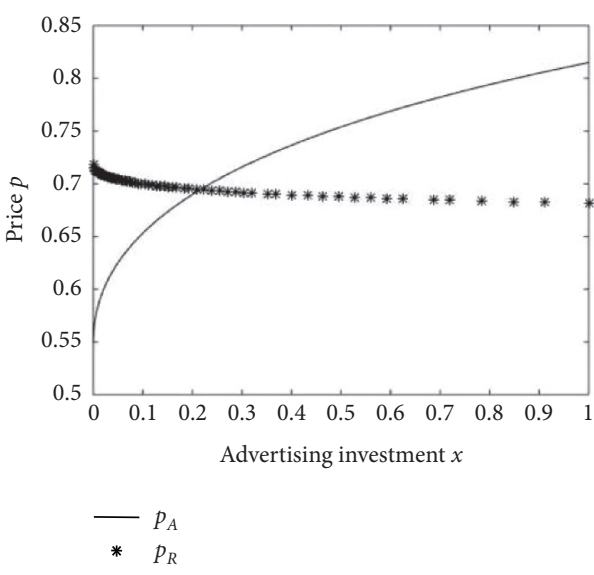

(a)

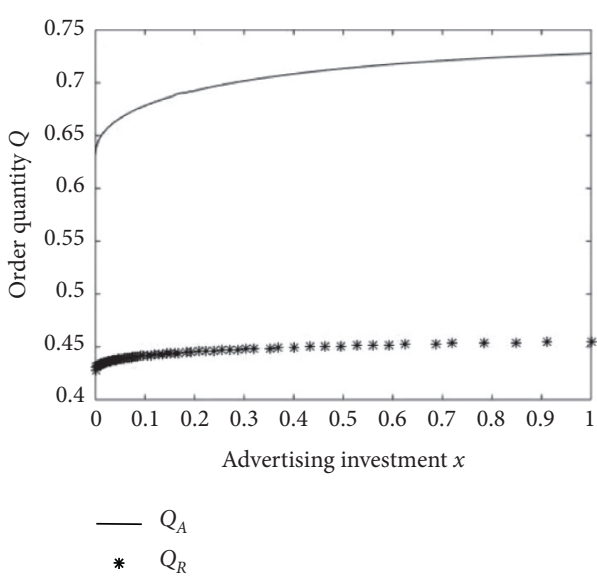

(b)

FIGURE 4: The influence of advertising investment on optimal price and optimal order quantity.

\section{Conclusion}

Based on the integrated sales model of advance selling and spot selling, this paper distinguishes consumers according to whether they know the advance-selling information of e-commerce retailers, considers the consumers' valuation of products, constructs the revenue function, respectively, under the consideration of e-commerce retailers' advanceselling advertising or spot-selling advertising, and analyzes the optimal strategy of advertising investment, pricing, and order quantity of fresh agricultural products e-commerce retailers. Through the solution of the model and numerical analysis in two modes, the following conclusions are obtained, hoping to provide the basis for the actual market operation of fresh agricultural products' e-commerce retailers in the e-commerce environment.

The conclusions are as follows: (1) e-commerce retailers can increase the total profit by advertising investment in both advance-selling period and spot-selling period; however, the growth of demand by advertising investment is limited, the optimal advertising investment needs to be adjusted according to the advertising effect factor. (2) Uncertainty demand in a certain range can increase the profit of e-commerce retailers. Compared with the case of fixed sales volume, e-commerce retailers' profit is greater when the sales volume is uncertain. However, when this kind of uncertainty becomes too much, it would cause the loss of retailers. Therefore, e-commerce retailers should view the uncertainty in demand correctly. (3) When e-commerce retailers advertise in the advance-selling period, they need to carry out corresponding discount activities. Under the influence of dual marketing means, consumers' demand is greater and the profits are greater. (4) When the demand stochastic factor $z>0$, e-commerce retailers should choose to invest advertising costs in the spot-selling period; when the demand stochastic factor $z<0$, e-commerce retailers should choose to invest advertising costs in the advanceselling period. (5) When the advertising investment is small, if you choose to put the advertising in the spot-selling period, the optimal pricing of the product in the spot-selling period should be higher than it in the advance-selling period; when the advertising investment is large, if you choose to put the advertising in the spot-selling period, the optimal pricing of the product in the spot-selling period should be lower than that in the advance-selling period. (6) With the increase of advertising investment, the total profit of advertising in the advance-selling period is greater than that in the cash sale period.

Further research of this paper can be carried out from the following aspects:

(1) This paper only considers the sales strategy of a single e-commerce retailer, and further study can consider the presale pricing problem in the competitive environment

(2) This paper only considers the case that consumers' risk preference is neutral, and further study can analyze the case that consumers' risk preference is different

(3) As many researchers have done with algorithm optimization [22], there are also some problems under complex and uncertain business environment which can be taken into consideration in future research.

\section{Data Availability}

All data, models, and code generated or used during the study are available within the article.

\section{Conflicts of Interest}

The authors declare that they have no conflicts of interest.

\section{Acknowledgments}

This work was supported by the National Natural Science Foundation of China, under Grant no. 71471073, and Fundamental Research Funds for the Central Universities, under Grant no. CCNU19TS078. 


\section{References}

[1] iResearch inc, Report on China's Fresh E-Commerce Industry in 2020, iResearch inc, Shanghai, China, 2020.

[2] S. M. Shugan and J. H. Xie, "Advance-selling as a competitive marketing tool," International Journal of Research in Marketing, vol. 22, no. 3, pp. 351-373, 2004.

[3] J. X. Zhang, J. Li, L. Lu, and R. Dai, "Supply chain performance for deteriorating items with cooperative advertising," Journal of Systems Science and Systems Engineering, vol. 26, no. 1, pp. 23-49, 2017.

[4] L. Yang and H. Li, "Research on retailers advance selling strategy considering the influence of advertising on demand," Advances in Social Science, Education and Humanities Research, vol. 237, pp. 38-42, 2018.

[5] S. H. Cho and S. C. Tang, "Advance selling in a supply chain under uncertain supply and demand," Operations Research, vol. 54, no. 5-6, pp. 531-532, 2014.

[6] A. Prasad, K. E. Stecke, and X. Zhao, "Advance selling by a newsvendor retailer," Production and Operations Management, vol. 20, no. 1, pp. 129-142, 2011.

[7] L. Xiao, M. Xu, M. Chen, and X. Guan, "Optimal pricing for advance selling with uncertain product quality and consumer fitness," Journal of the Operational Research Society, vol. 70, no. 9, pp. 1457-1474, 2019.

[8] Y. Cheng, H. Li, and A. Thorstenson, "Advance selling with double marketing efforts in a newsvendor framework," Computers \& Industrial Engineering, vol. 118, pp. 352-365, 2018.

[9] Y. Yu, J. Liu, X. Han, and C. Chen, "Optimal decisions for sellers considering valuation bias and strategic consumer reactions," European Journal of Operational Research, vol. 259, no. 2, pp. 599-613, 2016.

[10] W. S. Lim and C. S. Tang, "Advance selling in the presence of speculators and forward-looking consumers," Production and Operations Management, vol. 22, no. 3, pp. 571-587, 2013.

[11] X. Zhao and K. E. Stecke, "Pre-orders for new to-be-released products considering consumer loss aversion," Production and Operations Management, vol. 19, no. 2, pp. 198-215, 2010.

[12] E. P. Chew, C. Lee, R. Liu, K. Hong, and A. Zhang, "Optimal dynamic pricing and ordering decisions for perishable products," International Journal of Production Economics, vol. 157, pp. 39-48, 2014.

[13] R. Schaaf and B. Skiera, "Effect of time preferences on optimal prices and profitability of advance selling," Customer Needs and Solutions, vol. 1, no. 2, pp. 131-142, 2014.

[14] R. Maihami and I. N. Kamalabadi, "Joint pricing and inventory control for non-instantaneous deteriorating items with partial backlogging and time and price dependent demand," International Journal of Production Economics, vol. 136, no. 1, pp. 116-122, 2012.

[15] B. He, X. H. Gan, and K. F. Yuan, "Entry of online presale of fresh produce: a competitive analysis," European Journal of Operational Research, vol. 272, no. 1, pp. 339-351, 2018.

[16] T. J. Fan, X. Chang, and T. Feng, "Dynamic pricing and replenishment policy for fresh produce," Computers \& Industrial Engineering, vol. 139, pp. 106127.1-106127.14, 2020.

[17] H. Y. Zhang, H. Y. Xu, and X. J. Pu, "Comparisons of pre-sale strategies for a fresh agri-product supply chain with service effort," Agriculture, vol. 10, no. 8, 324 pages, 2020.

[18] J. Xie and J. C. Wei, "Coordinating advertising and pricing in a manufacturer-retailer channel," European Journal of Operational Research, vol. 197, no. 2, pp. 785-791, 2009.
[19] M. Nerlove and K. J. Arrow, "Optimal advertising policy under dynamic conditions," Economica, vol. 29, no. 114, pp. 129-142, 1962.

[20] S. Ray, "An integrated operations-marketing model for innovative products and services," International Journal of Production Economics, vol. 95, no. 3, pp. 327-345, 2005.

[21] J. Wang, Y. Li, F. Ye, and Q. Chen, "Optimal introduction time decision for holiday products with uncertain market demand," International Journal of Production Research, vol. 55, no. 1, pp. 161-175, 2017.

[22] L. Wang, L. Peng, S. Wang, and S. Liu, "Advanced backtracking search optimization algorithm for a new joint replenishment problem under trade credit with grouping constraint," Applied Soft Computing, Article ID 105953, 2020. 